\title{
Advance in Pre-Clinical Pharmacokinetics of Paeoniflorin, a Major Monoterpene Glucoside from the Root of Paeonia lactiflora
}

\author{
Orleans N. K. Martey ${ }^{1,2}$, Xiaoyan Shi ${ }^{1}$, Xin $\mathrm{He}^{1,3^{*}}$ \\ ${ }^{1}$ School of Chinese Materia Medica, Tianjin University of Traditional Chinese Medicine, Tianjin, China; ${ }^{2}$ Centre for Scientific Re- \\ search into Plant Medicine, Akwapim-Mampong, Ghana; ${ }^{3}$ Tianjin State Key Laboratory of Modern Chinese Medicine, Tianjin, \\ China. \\ Email: *hexintn@163.com
}

Received July $27^{\text {th }}, 2013$; revised August $29^{\text {th }}, 2013$; accepted September $15^{\text {th }}, 2013$

Copyright (C) 2013 Orleans N. K. Martey et al. This is an open access article distributed under the Creative Commons Attribution License, which permits unrestricted use, distribution, and reproduction in any medium, provided the original work is properly cited.

\begin{abstract}
Paeoniflorin (PF) is one of the main bioactive components of total glucosides of paeony (TGP) extracted from the root of Paeonia lactiflora Pall. TGP exhibit various biological activities such as improvement in memory, hepatoprotection, antimutagenic properties and platelet aggregation inhibition. The aim of this paper is to review the pharmacokinetics (PK) of PF as a pure compound and in single or multiple herb(s) of traditional Chinese medicine (TCM) prescriptions. The distribution of PF or PF in TCM fitted one or two compartmental model after oral administration or intravenous injection, respectively. However, PF has a low bioavailability (BA) in rabbit (7.24\%) and rat (3.24\%) after oral administration. The PK profiles and BA of PF were remarkably improved when co-administered with sinomenine or glycyrrhizin acid. The PK profiles and BA of PF in Radix Paeonia Rubra (RP-R) and Jing-zhi guan-xin were improved, but in co-administration of RP-R with Radix Angelicae Sinensis, the BA was significantly reduced. PK profiles and BA of PF in Shan yao gan-cao tang or Danggui-Shaoyao-San was either remarkably improved or not. However, neither the PK profiles nor the BA of PF in Radix paeonia alba, Huangqin-tang Si ni san or Tang-Min-Ling-Wan was improved. Metabolism in the liver did not play any role in the low oral BA of PF. The low BA was thus attributed to poor permeation due to low lipophilicity, P-glycoprotein mediated efflux, intestinal bacteria and hydrolytic degradation in the intestine by the intestinal brush border lactase phlorizin hydrolase (LPH) and certain esterases. These findings show the in vivo course of PF and provide information on the maximum biological actions of PF that may help traditional Chinese herbal medicinal practitioners.
\end{abstract}

Keywords: Bioavailability; Intestinal Bacteria; Pharmacokinetics; Paeoniflorin (PF); P-glycoprotein (P-gp)

\section{Introduction}

Paeonia lactiflora Pall is a Chinese herb commonly known as Baishao or white peony (Figure 1) from the Ranunculaceae family. According to traditional Chinese medicine (TCM), P. lactiflora functions either as a single herb or in combination for nourishing blood and Yin, calming the liver to relieve pain and suppressing hyperactive liver-Yang. P. lactiflora is used as an analgesic, anti-inflammatory and antispasmodic drug in the treatment of amenorrhea, dysmenorrhea, and pain in the chest and abdomen. Radix Paeoniae is also used to treat dementia, headache, vertigo, spasm of the calf muscles, liver disease, and allergies, and as an anticoagulant [1-4].

${ }^{*}$ Corresponding author.
Chemical compounds isolated from $P$. latiflora include pentagalloylglucose, paeonilactones $\mathrm{A}, \mathrm{B}$ and $\mathrm{C}$, paeonol, benzoic acid, trihydroxybenzoic acid, gallic acid and monoterpene glucosides such as paeoniflorin, oxypaeoniflorin, isobenzoylpeoniflorin, 4'-O-methyl-paeoniflorin, isopaeoniflorin, isobenzoylpeoniflorin 3'-O-galloyl-paeonifloin, 4'-O-galloypaeoniflorin, albiflorin, 4'-O-galloylalbiflorin, 6'-O-beta-D-glucopyranosylalbiflorin, and 6'-Obenzoylalbiflorin [5-9].

Paeoniflorin (PF) (Figure 2(a)), the major bioactive monoterpene glucoside from $P$. lactiflora is characterised as a neutral compound (MW 428.47) with good solubility ( $\log \mathrm{P}=2.88$ ) indicating low lipophilicity (http://www. chemnetbase.com). Pharmacological studies have indicated that PF has anti-inflammatory [10], anti-coagulant 


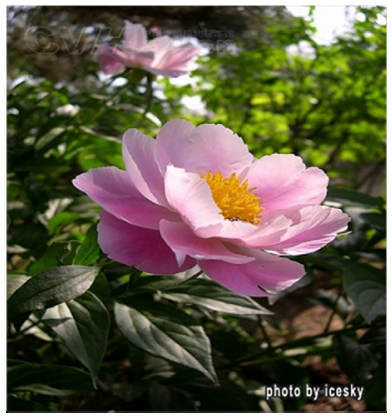

(a)

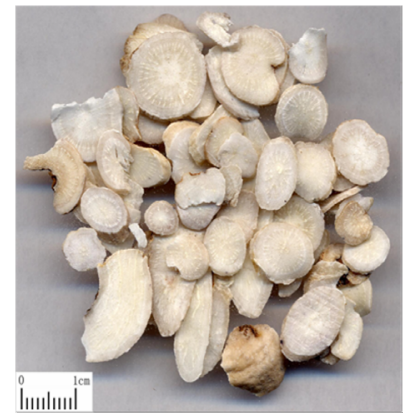

(b)
Figure 1. Picture of a P. lactiflora plant (a) and dried roots (b).

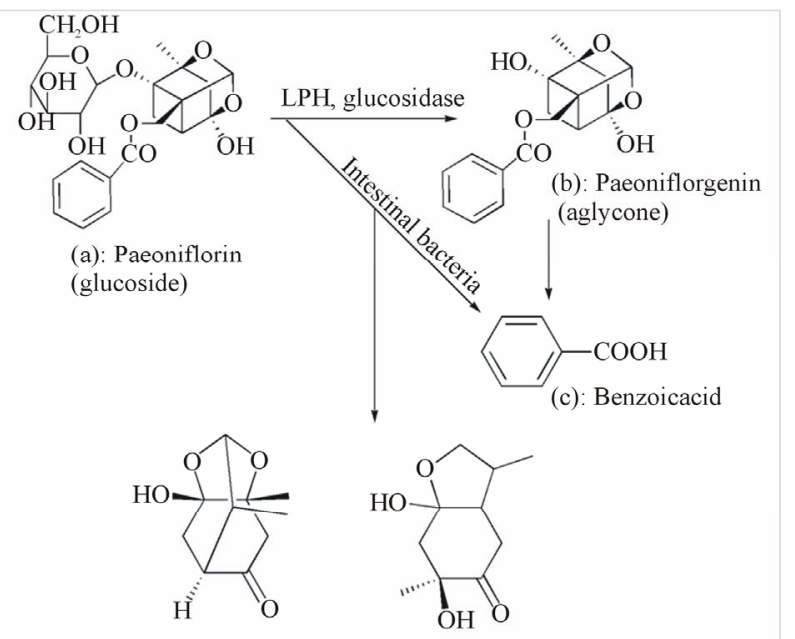

(d): 7S-or 7R-Paeonimetabolin I

(e): Paeonimetabolin II

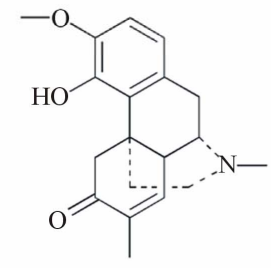

(f): Sinomenin

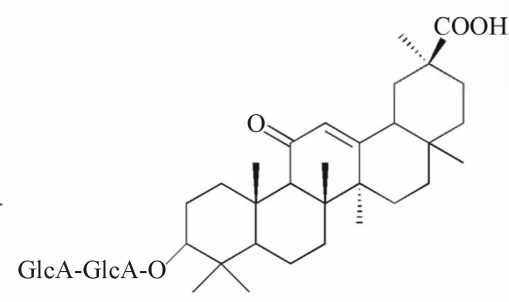

(g): Glycyrrhizin acid
Figure 2. Proposed metabolic pathways of paeoniflorin in the intestine and structures of other compounds that play a role in its pharmacokinetics.

[11], neuromuscular blocking [12], cognition-enhancing [13-15], anti-hyperglycemic [16] and neuroprotective [17, 18 ] effects. Knowledge of bioactive constituents of medicinal herbs with favorable pharmacokinetic properties is essential for understanding the relationship between consumption and pharmacological effects with the view of identifying therapeutic principles in herbal medicines. Different from single compound of Western drug, TCM is a complex system consisting of multiple compounds. Pharmacokinetic studies are valuable in evaluating the rationality and compatibility of herbs and prescription due to the complexity of chemical compounds present. Normally, one major active ingredient is selected as the indicative compound and the interactions of ingredients in the herb or prescription are clarified based on the pharmacokinetic behaviour of the selected compound. Hence, the development of pharmacokinetic study on PF, the major bioactive monoterpene glucoside of $P$. lactiflora, as a pure compound and in single or multiple herb(s) of TCM Prescriptions was reviewed in this paper.

\section{Pharmacokinetics and Poor Oral Bioavailability of PF as a Pure Compound}

\subsection{Pharmacokinetics of $P F$ as a Pure Compound}

The pharmacokinetics of PF as a pure compound has been studied in different species and different routes of administration. The plasma concentration-time curve for dog, rabbit and rat in different papers showed speciesindependency after intravenous injection [19-23] (Table 1). The logarithmic plasma concentration-time curve of $\mathrm{PF}(30 \mathrm{mg} / \mathrm{kg})$ in rats after intravenous injection showed a rapid decline initially but then slowed eventually (Wang et al. 2008), thus resulting in a biphasic curve characterized by $\mathrm{C}=\mathrm{C}_{1} \mathrm{e}^{-\lambda 1 \mathrm{t}}+\mathrm{C}_{2} \mathrm{e}^{-\lambda 2 \mathrm{t}}$, that is, the sum of two exponential terms $\mathrm{C}_{1} \mathrm{e}^{-\lambda 1 \mathrm{t}}$ and $\mathrm{C}_{2} \mathrm{e}^{-\lambda 2 \mathrm{t}}$, where $\mathrm{C}_{1}$ and $\mathrm{C}_{2}$ refer to the plasma drug concentration given by the corresponding zero-time intercept, and $\lambda$ is the rate constant with an associated half-life, t. This distribution could therefore be fitted into a two-compartment model as distribution equilibrium is reached between plasma and highly perfused tissues with further redistri-bution from well-perfused tissues to less-perfused tissues during

Table 1. Pharmacokinetic parameters of the intravenous injection of pure paeoniflorin in rabbits, dogs and rats at different doses.

\begin{tabular}{cccc}
\hline Parameter $(\mathrm{s})$ & $\begin{array}{c}\text { Rabbit } \\
(\mathrm{n}=5)\end{array}$ & $\begin{array}{c}\text { Dog } \\
(\mathrm{n}=3)\end{array}$ & $\begin{array}{c}\text { Rat } \\
(\mathrm{n}=8)\end{array}$ \\
\hline Dose $(\mathrm{mg} / \mathrm{kg})$ & 25.00 & 11.25 & 30.00 \\
$\mathrm{t}_{1 / 2 \alpha}(\mathrm{min})$ & $5.93 \pm 2.69$ & $6.30 \pm 1.80$ & $32.4 \pm 16.8$ \\
$\mathrm{t}_{1 / 2 \beta}(\mathrm{min})$ & $66.02 \pm 27.63$ & $133.4 \pm 84.9$ & $280.2 \pm 108.6$ \\
$\mathrm{~K}_{21}(1 / \mathrm{min})^{\mathrm{a}}$ & $0.052 \pm 0.031$ & $0.019 \pm 0.007$ & $0.0025 \pm 0.0016$ \\
$\mathrm{~K}_{10}(1 / \mathrm{min})^{\mathrm{b}}$ & $0.035 \pm 0.006$ & $0.004 \pm 0.008$ & $0.019 \pm 0.008$ \\
$\mathrm{~K}_{12}(1 / \mathrm{min})^{\mathrm{c}}$ & $0.069 \pm 0.036$ & $0.066 \pm 0.024$ & $0.0051 \pm 0.0092$ \\
$\mathrm{~V}_{\mathrm{C}}(\mathrm{mL} / \mathrm{kg})$ & $165.4 \pm 59.7$ & $84.5 \pm 13.6$ & - \\
$\mathrm{V}_{\mathrm{B}}(\mathrm{mL} / \mathrm{kg})$ & $516.8 \pm 0.32$ & $539.2 \pm 104.2$ & $450 \pm 250$ \\
$\mathrm{CL}(\mathrm{mL} / \mathrm{min} / \mathrm{kg})$ & $6.11 \pm 3.29$ & $3.40 \pm 1.00$ & $7.66 \pm 0.23$ \\
\hline
\end{tabular}

Values represent: mean $\pm \mathrm{SD} ;{ }^{a} \mathrm{~K}_{21}$ : Transfer rate constant from the peripheral compartment (2) to the central compartment (1); ${ }^{b} \mathrm{~K}_{10}$ : Elimination rate constant from the central compartment. ${ }^{c} \mathrm{~K}_{12}$ : Transfer rate constant from the central compartment (1) to the peripheral compartment (2). 
subsequent decline. However, a logarithmic plasma concentration-time curve of PF $(300 \mathrm{mg} / \mathrm{kg})$ after oral administration in rats showed fast absorption with a terminal linear decline of plasma concentration characterised by the monoexponential equation $\mathrm{C}=\mathrm{C}_{(0)} \mathrm{e}^{-\lambda \mathrm{t}}$. This distribution could therefore be fitted into a one-compartmental model as equilibrium is rapidly reached between plasma and highly perfused tissues [22].

PF have a low bioavailability of about $(7.24 \pm 4.15) \%$ after $250 \mathrm{mg} / \mathrm{kg}$ intragastric (ig) dose in rabbits [19], and about $(3.12 \pm 0.76) \%$ after oral administration in rats [21-23]. Takeda et al. [24] showed that the cumulative urinary and fecal excretions of PF at $5 \mathrm{mg} / \mathrm{kg}$ dose after intravenous injection were $50.5 \%$ and $0.22 \%$ of the dose within $7 \mathrm{~h}, 1.0 \%$ and $0.08 \%$ of the dose after oral administration within $48 \mathrm{~h}$, respectively. The cumulative bile excretion after intravenous or oral administration in rats at a dose of $0.5 \mathrm{mg} / \mathrm{kg}$ were $6.9 \%$ and $1.3 \%$ of the doses within $24 \mathrm{~h}$, respectively. The total renal and bile clearance was less than the total clearance value. This conforms to the findings of Chen et al. [20] who found out that after the ig administration of $550 \mathrm{mg} / \mathrm{kg}$ of PF, $10 \%$ and $1 \%$ of $\mathrm{PF}$ were removed from rat feces and urine, respectively, and that $8.64 \%$ could be recovered from the rat bile within $7 \mathrm{~h}$ after $55 \mathrm{mg} / \mathrm{kg}$ intravenous administration. PF was also rapidly removed from the blood by the kidney to $36.85 \%$ in $20 \mathrm{~min}$ and $79.33 \%$ in $7 \mathrm{~h}$ of the accumulated recovery amount of excretion after $11.25 \mathrm{mg} / \mathrm{kg}$ total intravenous doses administered to dogs. An accumulated amount of only $3.77 \%$ within $7 \mathrm{~h}$ was also found in the bile after intravenous administration [19]. These results may be due to poor absorption from the gastrointestinal tract, decomposition in the intestine by bacterial microflora, and/or first-pass elimination in the gut wall or liver.

\subsection{Poor Oral Bioavailability of PF in Vivo}

$\mathrm{PF}$ as a single compound has a wide range of pharmacological actions but low bioavailability. In an in vivo assessment to estimate the first pass elimination by intestinal flora, the extraction ratios of PF in the gut wall, liver and lungs were assessed by comparing the AUCs after various routes of administration [21]. The plasma concentration profile of PF after intraportal administration $[(0.5$ and 5$) \mathrm{mg} / \mathrm{kg}]$ was close to that of intravenous administration. The mean pulmonary extraction ratio from the veins and the arteries was also estimated to be 0.06 . These findings suggest that PF has a negligible hepatic extraction ratio and that it is not metabolized in liver and lungs. Rather, the unbound fraction is degraded by intestinal flora (Bacteroides fragilis or Lactobacillus brevis) to form the $7 \mathrm{~S}$ and $7 \mathrm{R}$ isomers of paeonimetaboline I as major metabolites, along with the $7 \mathrm{R}$ and $7 \mathrm{~S}$ isomers of paeonimetaboline II as minor metabolites [25,26] (Figure 2).

Liu et al. studied the action of lactase phlorizin hydrolase (LPH, a brush border membrane-associated enzyme in intestinal cells that hydrolyse lactose) to PF using a single-pass four site rat intestinal perfusion model. There was significant decrease of PF to paeoniflorigenin $(>80 \%)$ in the perfusate in the presence of LPH inhibitor, gluconolactone, with a lower apparent absorption in the upper small intestine. In this region, LPH is more active and esterases catalyse the hydrolysis of PF to form benzoic acid [27] (Figure 2).

\section{Pharmacokinetics of PF in TCM Prescriptions}

\subsection{Pharmacokinetics of PF in a Single-Herb Prescription}

Radix paeonia rubra (RP-R) and radix paeonia alba (RP-A) are two independent traditional Chinese herbal medicines, both of which are obtained from the root of $P$. lactiflora Pall. (Figure 1(b)) and have different pharmacological actions. The former is obtained directly from the dried roots of $P$. lactiflora Palls. grown wild, while the latter is from a decoction of the dried peeled roots of P. lactiflora Pall. grown domestically. RP-R reportedly exhibits pharmacological actions against coronary diseases (e.g., angina pectoris, chronic-cardiac ischemia, ventricular tachycardia, augmenting blood of coronary artery, anti-acute myocardial ischemia); it also features antiplatelet aggregation, anti-thrombogenesis, activation of fibrinolysis, antihyperlipidaemic effect, improvements in blood hypervisicosity syndrome and decreased blood pressure, anti-atherosclerosis, heart or liver protection, antitumor effects, and protection of neurons against kainic acid-induced neurotoxicity $[28,29]$. RP-A has been reported to exhibit anti-inflammatory, anti-viral, spasmolytic, analgesic and liver protection effects [30,31].

The pharmacokinetic differences of PF have been investigated in RP-R and RP-A with respect to its low bioavailability following oral administration in aqueous PF solution, decoction of RP-R and RP-A at doses of 300 $\mathrm{mg} / \mathrm{kg} \mathrm{PF}$ content by oral gavages in rats using a simple high-performance liquid chromatography (HPLC) method [22]. The oral absorption kinetics of PF in RP-R and RP-A were influenced when compared to PF alone following oral administration (Table 2). The absorption half-life of PF in RP-R was much delayed followed by PF in RP-A and then by PF alone. The peak time $\left(t_{\max }\right)$ occurred much longer in RP-R followed by RP-A and then by $\mathrm{PF}$ alone. This findings indicates that there was a delay in the absorption of PF until it reaches the value at which point the rate of elimination matches the rate of 
Table 2. Pharmacokinetic parameters of $P F$ in rats after oral administration of PF solution, RP-R and RP-A aqueous extracts at a dose containing $300 \mathrm{mg} / \mathrm{kg}$ of PF using a simple HPLC method.

\begin{tabular}{cccc}
\hline Parameters & Paeoniflorin & $\begin{array}{c}\text { Radix } \\
\text { Paeoniae ubra }\end{array}$ & $\begin{array}{c}\text { Radix } \\
\text { Paeoniae alba }\end{array}$ \\
\hline $\mathrm{K}_{\mathrm{e}}(1 / \mathrm{h})$ & $0.19 \pm 0.09$ & $0.20 \pm 0.03^{* *}$ & $0.12 \pm 0.04$ \\
$\mathrm{~K}_{\mathrm{a}}(1 / \mathrm{h})$ & $8.73 \pm 5.53$ & $1.55 \pm 0.79^{* *}$ & $5.10 \pm 3.43^{\circ}$ \\
$\mathrm{t}_{1 / 2 \alpha}(\mathrm{h})$ & $0.11 \pm 0.07$ & $0.54 \pm 0.20^{* * . *}$ & $0.16 \pm 0.09^{\circ}$ \\
$\mathrm{t}_{1 / 2 \beta}(\mathrm{h})$ & $4.27 \pm 1.57$ & $3.58 \pm 0.61^{*}$ & $6.19 \pm 2.06$ \\
$\mathrm{t}_{\max }(\mathrm{h})$ & $0.58 \pm 0.34$ & $1.67 \pm 0.43^{* * *}$ & $0.80 \pm 0.35^{\circ}$ \\
$\mathrm{C}_{\max }(\mu \mathrm{g} / \mathrm{mL})$ & $3.34 \pm 1.18$ & $3.69 \pm 1.46^{*}$ & $1.46 \pm 0.29^{\circ}$ \\
$\mathrm{AUC}(\mu \mathrm{g} \cdot \mathrm{h} / \mathrm{mL})$ & $18.85 \pm 7.54$ & $24.89 \pm 7.41^{* *}$ & $10.61 \pm 1.51^{\circ}$ \\
$\mathrm{CL}(\mathrm{h} \cdot \mathrm{L} / \mathrm{Kg})$ & $15.10 \pm 3.17$ & $12.62 \pm 3.48^{* *}$ & $21.12 \pm 7.52^{* *}$ \\
$\mathrm{Vd}(\mathrm{L} / \mathrm{Kg})$ & $90.56 \pm 32.81$ & $66.57 \pm 26.80^{* *}$ & $194.20 \pm 46.33^{* *}$ \\
$\mathrm{~F}_{\text {rel }}(\%)$ & 100 & 132.1 & 56.3 \\
\hline
\end{tabular}

Values represent: mean $\pm \mathrm{SD}$, oral administration of RP-R versus $\mathrm{RP}-\mathrm{A},{ }^{*} \mathrm{P}<$ $0.05 ;{ }^{* *} \mathrm{P}<0.01$, oral administration of RP-R, RP-A versus paeoniflorin solution: ${ }^{\circ} \mathrm{P}<0.05 ;{ }^{*} \mathrm{P}<0.01$.

absorption at maximum concentrations of PF in RP-R, $\mathrm{RP}-\mathrm{A}$ and $\mathrm{PF}$ alone, respectively. However, the significantly decreased $\mathrm{C}_{\max }$ of $\mathrm{PF}$ in RP-A with a corresponding decrease in the area under the concentration-time curve (AUC) of $(10.61 \pm 1.56) \mu \mathrm{g} \cdot \mathrm{h} / \mathrm{mL}$ showed that even though there was a delay of absorption of PF in RP-A, there was a decrease in bioavailability when compared to PF in RP-R and PF alone, with AUC of $(24.89 \pm 7.41) \mu \mathrm{g} \cdot \mathrm{h} / \mathrm{mL}$ and $(18.87 \pm 7.54) \mu \mathrm{g} \cdot \mathrm{h} / \mathrm{mL}$, respectively. These findings correspond to the remarkable improvement in the relative bioavailability of $\mathrm{PF}$ alone from $3.26 \%$ to $4.26 \%$ of PF in RP-R, but a remarkable decrease to $1.82 \%$ in RP-A after oral administration to rats.

In a similar study using an HPLC-electrospray ionization mass spectrometry, Feng et al. [32] investigated the pharmacokinetic properties of PF following oral administration of aqueous extracts of RP-R and RP-A containing $0.2 \mathrm{~g} / \mathrm{g}$ crude drug to rats. The results (Table 3) showed a higher $\mathrm{C}_{\max }$, higher $\mathrm{AUC}_{0-\infty}$, an increased $\mathrm{t}_{\max }$, a delayed $t_{1 / 2}$, and a lower $\mathrm{K}_{\mathrm{e}}$ of PF in RP-R than in RP-A with $\mathrm{C}_{\max }, \mathrm{AUC}_{0-\infty}, \mathrm{t}_{\max }, \mathrm{t}_{1 / 2}$ and $\mathrm{K}_{\mathrm{e}}$ at a significant difference $P<0.01$. This also supports the fact there was oral bioavailability increase of PF in RP-R than RP-A due to the significant increase in $\mathrm{AUC}$ and $\mathrm{C}_{\max }$ with a remarkable change in peak time.

Wu et al., (2008) also reported an $\mathrm{AUC}_{0-\mathrm{t}}[(4.6 \pm 0.85)$ $\mathrm{mg} \cdot \mathrm{h} / \mathrm{L}], \mathrm{C}_{\max }[(1.55 \pm 0.53) \mathrm{mg} / \mathrm{L}]$ and MRT $[(3.08 \pm$ $0.76) \mathrm{h}]$ of $\mathrm{PF}$ in RP-R. However, $\mathrm{AUC}_{0-\mathrm{t}}, \mathrm{C}_{\max }$, and MRT of PF in RP-R were significantly changed, $P<$ 0.05 , to $[(3.36 \pm 0.56) \mathrm{mg} \cdot \mathrm{h} / \mathrm{L} ;(0.9 \pm 0.42) \mathrm{mg} / \mathrm{L} ;(5.19 \pm$ $1.95) \mathrm{h}]$, respectively when RP-R was co-administrated
Table 3. Pharmacokinetic properties of PF following oral administration of aqueous extract of RP-R and RP-A containing $0.2 \mathrm{~g} / \mathrm{g}$ crude drug to rats using an HPLC-ESI-MS.

\begin{tabular}{ccc}
\hline Parameters & Radix Paeoniae rubra & Radix Paeoniae alba \\
\hline $\mathrm{t}_{1 / 2}(\mathrm{~h})$ & $1.86 \pm 0.27$ & $0.85 \pm 0.11$ \\
$\mathrm{~K}_{\mathrm{e}}(\mathrm{l} / \mathrm{h})$ & $0.35 \pm 0.10$ & $0.79 \pm 0.29$ \\
$\mathrm{t}_{\max }(\mathrm{h})$ & $0.67 \pm 0.07$ & $0.33 \pm 0.02$ \\
$\mathrm{C}_{\max }(\mathrm{ng} / \mathrm{mL})$ & $185.24 \pm 26.24$ & $34.44 \pm 13.42$ \\
$\mathrm{AUC}_{0-\mathrm{t}}(\mathrm{ng} \cdot \mathrm{h} / \mathrm{mL})$ & $48572.38 \pm 480.18$ & $288.66 \pm 80.38$ \\
$\mathrm{AUC}_{0-\infty}(\mathrm{ng} \cdot \mathrm{h} / \mathrm{mL})$ & $52274.73 \pm 489.32$ & $315.08 \pm 85.44$ \\
\hline
\end{tabular}

Values represent: mean \pm SD.

with Radix Angelicae Sinensis to rats using HPLCMS/MS method [33]. RP-R in the presence of Radix Angelicae Sinensis can significantly reduce the bioavailability of PF in RP-R. The kinetic process of paeoniflorin in plasma showed two compartment model after oral administration of RP-A extract at doses of $0.2,0.4,0.8$ $\mathrm{g} / \mathrm{kg}$ to rats using an HPLC-MS/MS method [34].

The differences between the plasma concentration profiles of PF in RP-R or RP-A compared to PF alone is evidence of drug-drug interactions as a result of different complex chemical compounds present in herbal medicines. This could occur either by induction of metabolic enzymes, P-glycoprotein, LPH, esterase's, or degradation by intestinal bacteria. It was reported by Feng et al. [32] that except for PF, the other monoterpene glycosides of albiflorin, benzoylpaeoniflorin and some acids of benzoic acid, trihydroxybenzoic acid were the common components existing in both drugs. Paeonol and paeoniflorinsulfite were characteristic chemical constituents for RP-R and RP-A, respectively. The content of albiflorin and oxypaeoniflorin in RP-A was larger than that in RP-R, while the content of $\mathrm{PF}$ and benzoic acid was higher in RP-R than that in RP-A. RP-R as a decoction may be more useful clinically in TCM hospitals as evidenced by the pharmacokinetic profiles above.

Patients are the final users of drugs and it will be interesting if pharmacokinetics studies are considered in animal models compared to normal animals. In a study, Jiang et al. [35], investigated the pharmacokinetics of PF in RP-R following intragastric administration of RP-R powder (low dose: $7 \mathrm{~g} / \mathrm{kg}$ or high dose: $14 \mathrm{~g} / \mathrm{kg}$ containing $357 \mathrm{mg} / \mathrm{kg}$ or $714 \mathrm{mg} / \mathrm{kg}$ PF, respectively) to normal rats (NR) and alpha-naphthylisothiocyanate induced acute cholestasis hepatitis $(\mathrm{ACH})$ rats using Ultra Performance Liquid Chromatography (UPLC)-ESI-MS/MS method. This showed remarkable improvement in absorption kinetics in both low dose (LD) and high dose (HD) administered with increased $\mathrm{AUC}_{0-\mathrm{t}}$, increased $\mathrm{AUC}_{0-\infty}$, high $\mathrm{t}_{\max }$ and reduced $\mathrm{CLz} / \mathrm{F}$ in the $\mathrm{ACH}$ rats compared to that of the normal rats with corresponding parameters shown 
in Table 4. The induced cholestasis is characterized by periportal bile duct epithelial degeneration and necrosis and a pronounced neutrophil infiltration which results in low levels of cytochrome P450 [36,37]. The increase in plasma concentrations and decreased clearance of $\mathrm{PF}$ in $\mathrm{ACH}$ rats compared to NR may be due to the disease condition. Similar results were observed by He et al. [38] on the effect of cerebral Ischemia-reperfusion (CIR) on pharmacokinetic fate of paeoniflorin after intravenous administration of Paeonia radix extract (at $60 \mathrm{mg} / \mathrm{kg} \mathrm{PF}$ ) to rats using an HPLC method. The CIR significantly, $P$ $<0.05$, increased, AUC $[(9626.00 \pm 1053.98) \mu \mathrm{g} \cdot \mathrm{min} /$ $\mathrm{mL}]$, decrease CL $[(0.0071 \pm 0.0013) \mathrm{mg} /(\mathrm{kg} \cdot \mathrm{min})]$ and prolong the half-life of distribution $\left[\mathrm{t}_{1 / 2 \alpha}(2.04 \pm 0.84)\right.$ $\mathrm{min}]$ and elimination $\left[\mathrm{t}_{1 / 2 \beta}(24.51 \pm 9.23) \mathrm{min}\right]$ compared to normal rats with corresponding parameters as (5338.71 $\pm 467.54) \mu \mathrm{g} \cdot \mathrm{min} / \mathrm{mL},(0.0162 \pm 0.0023) \mathrm{mg} /(\mathrm{kg} \cdot \mathrm{min})$, $0.69 \pm 0.19) \mathrm{min}$ and $(18.77 \pm 3.74) \mathrm{min}$.

\subsection{Pharmacokinetics of $P F$ in Multiple-Herb Prescription}

The pharmacokinetics of PF in single-herb extracts had been shown to be influenced by the complexity of other phytochemicals that may be present. Most TCM prescriptions are multiple herbal formulations. Thus, knowledge of the pharmacokinetics of marker compounds in the presence of other herbs cannot be overemphasised primarily due to its relevance to the biological actions or otherwise of the herbal prescription. Shao-yao GancaoTang (SGT), which is composed of Radix P. lactiflora and Radix Glycyhhizea uralensis, is one of the most famous Chinese prescriptions. SGT is widely used in China and Japan for acute abdominal pain and muscles stiffness. The pharmacokinetics of PF following oral administration of $2 \mathrm{mg} / \mathrm{ml} \mathrm{SGT}$ extract (containing 10 $\mathrm{mg} / \mathrm{kg}$ PF) to mouse using a simple and rapid HPLC method was significantly improved compared to the kinetics data of PF after oral administration of Paeoniae Radix extract alone [39]. The results and the previously reported kinetic data of PF after oral administration of Paeoniae Radix extract alone (Table 5), showed high $t_{\max }$, increased $C_{\max }$, increased $\mathrm{AUC}_{0-\mathrm{t}}$, decreased $\mathrm{V}_{\mathrm{d}} / \mathrm{F}$, $\left(\mathrm{V}_{\mathrm{d}}\right.$ means apparent volume of distribution, $\mathrm{F}$ means bioavailability), reduced $\mathrm{CL} / \mathrm{F}$ and prolonged $\mathrm{t}_{1 / 2}$, respectively. Therefore the absorption kinetics and bioavailability significantly, $P<0.01$, improve since the $\mathrm{C}_{\max }$ and AUC value increase with an increase in the peak time. This therefore took longer for the amount of PF to reach the value at which the rate-step limiting matches the rate of absorption $\mathrm{C}_{\max }$. This conclusion conforms with Shen et al. [40] that, generally, the absorption of Shaoyao (Paeoniae Radix) components in SGT was increased when
Table 4. Pharmacokinetics of PF in RP-R following intragastric administration of RP-R powder to normal (NR) and alpha-naphthylisothiocyanate induced acute cholestasis heaptitis $(\mathrm{ACH})$ rats.

\begin{tabular}{ccccc}
\hline \multirow{2}{*}{ Parameters } & \multicolumn{4}{c}{ Normal Rats } \\
\multicolumn{4}{c}{ RP-R Powder $(\mathrm{g} / \mathrm{kg})$} \\
\cline { 2 - 5 } & 7 & 14 & 7 & 14 \\
\hline $\begin{array}{c}\mathrm{AUC} \mathrm{C}_{0-\mathrm{t}} \\
(\mathrm{mg} \cdot \mathrm{h} / \mathrm{L})\end{array}$ & $8.14 \pm 0.62$ & $16.58 \pm 0.92$ & $15.62 \pm 3.1$ & $31.71 \pm 3.00$ \\
$\begin{array}{c}\mathrm{AUC} \mathrm{C}_{0-\infty} \\
(\mathrm{mg} \cdot \mathrm{h} / \mathrm{L})\end{array}$ & $9.64 \pm 1.12$ & $20.5 \pm 0.61$ & $17.27 \pm 4.59$ & $34.87 \pm 4.03$ \\
$\mathrm{t}_{\max }(\mathrm{h})$ & $0.08 \pm 0.00$ & $0.44 \pm 0.21$ & $0.38 \pm 0.16$ & $0.58 \pm 0.20$ \\
$\begin{array}{c}\mathrm{CLz} / \mathrm{F} \\
(\mathrm{L} / \mathrm{h} / \mathrm{kg})\end{array}$ & $37.40 \pm 4.18$ & $34.78 \pm 1.05$ & $21.59 \pm 4.59$ & $20.69 \pm 2.41$ \\
\hline
\end{tabular}

Values represent: mean \pm SD.

looking at the pharmacokinetics of characteristic effective ingredients from individual and combination Shaoyao and Gancao (Glycyrrhizae Radix) treatment in rats using HPLC fingerprinting. In contrast, Gan et al. [41] reported low bioavailability of PF in SGT compared to $\mathrm{PF}$ in Radix Paeonea decoction following oral administration of $60 \mathrm{~g} / \mathrm{kg}$ SGT and $30 \mathrm{~g} / \mathrm{kg}$ Radix paeonea decoction $(165.7 \mathrm{mg} / \mathrm{kg}$ and $182.27 \mathrm{mg} / \mathrm{kg} \mathrm{PF})$ to rats using an UPLC method. The results showed decrease in $\mathrm{AUC}_{0-\mathrm{t}}$ $[(2903 \pm 92$ vs $3846 \pm 477) \mu \mathrm{g} \cdot \mathrm{h} / \mathrm{L}], \mathrm{AUC}_{(0-\infty)}[(2736 \pm$ 164 vs $4046 \pm 514) \mu \mathrm{g} \cdot \mathrm{h} / \mathrm{L}], \mathrm{AUC}_{0 \text {-t/dose }}[(15.78 \pm 0.84 \mathrm{vs}$ $21.05 \pm 2.61) \mu \mathrm{g} \cdot \mathrm{h} / \mathrm{L} /(\mathrm{mg} / \mathrm{kg})]$, and $\mathrm{AUC}_{(0-\infty) / \text { dose }}[(16.51$ \pm 0.99 vs $22.14 \pm 2.81) \mu \mathrm{g} \cdot \mathrm{h} / \mathrm{L} /(\mathrm{mg} / \mathrm{kg})]$ and high CL/F [(60.8 \pm 3.7 vs $45.9 \pm 7.1) \mathrm{L} / \mathrm{h} / \mathrm{kg}]$ of PF in SGT and radix paeonea decoction, respectively.

The pharmacokinetic parameters (Table 5) of PF of Jing-Zhi-Guan-Xin (JZGX), composed of Radix Salviae Miltiorrhizae, Radix Paeoniae Rubrae, Rhizoma Chuanxiong, Flos Carthami, and Lignum Dalbergiae Odorafera, were remarkably improved when compared with that of Paeoniae Radix extract alone (longer $t_{\max }$, increased $\mathrm{C}_{\max }$; increased $\mathrm{AUC}_{0-\infty}$, longer MRT and a longer $\mathrm{t}_{1 / 2}$ ) after oral administration, indicating that the absorption of PF after the oral administration of JZGX tablets was significantly greater than that of Paeoniae Radix extract alone and that it occurred with a significant increase in AUC after oral administration of JZGX tablets. These findings suggest that relatively more PF was absorbed [42].

Danggui-Shaoyao-San (DSS), composed of Radix Angelica sinesis, Radix P. lactiflora, Sclerotium poriae Cocos, Rhizoma Atractylodis macrocephalae, Rhizoma Alisma orientalis and Radix Linguistici wlichii, is clinically used for the treatment of vascular dementia (VD). The pharmacokinetics of PF (Table 6), either in pure form $(224 \mathrm{mg} / \mathrm{kg})$ or in DSS $(3.54 \mathrm{~g} / \mathrm{kg}$ containing 224 $\mathrm{mg} / \mathrm{kg} \mathrm{PF}$ ) following oral administration to VD rats 
Table 5. Pharmacokinetics parameters of PF following oral administration of SGT and JZGH to mouse and beagle dogs respectively compared to kinetic data of Radix poeny extracts (RPE).

\begin{tabular}{cccc}
\hline Parameters & RPE & SGT & JZGH \\
\hline $\mathrm{t}_{\max }(\mathrm{min})$ & $14.0 \pm 4.18$ & $17.0 \pm 4.47$ & $130.00 \pm 30.98^{*}$ \\
$\mathrm{C}_{\max }(\mathrm{ng} / \mathrm{mL})$ & $86.34 \pm 18.67$ & $111.56 \pm 20.83^{*}$ & $210.49 \pm 23.89^{*}$ \\
$\mathrm{AUC}_{0-\mathrm{t}}(\mathrm{ng} \cdot \mathrm{min} / \mathrm{mL})$ & $8126.97 \pm 2004.62$ & $12293 \pm 1945.96^{*}$ & - \\
$\mathrm{AUC}_{0-\infty}(\mathrm{ng} \cdot \mathrm{min} / \mathrm{mL})$ & $9746.10 \pm 2554.62$ & $16335 \pm 3641.46^{*}$ & $43066.50 \pm 10119.51^{*}$ \\
$\mathrm{t}_{1 / 2}(\mathrm{~min})$ & $94.00 \pm 12.35$ & $116.17 \pm 35.02$ & $147.52 \pm 28.98^{*}$ \\
$\mathrm{CL} / \mathrm{F}(\mathrm{mL} / \mathrm{min} / \mathrm{kg})$ & $1113.35 \pm 420.63$ & $644.74 \pm 84.45^{*}$ & - \\
$\mathrm{Vd} / \mathrm{F}(\mathrm{L} / \mathrm{kg})$ & $147.44 \pm 40.78$ & $103.05 \pm 20.45^{*}$ & - \\
$\mathrm{MRT}(\mathrm{min})$ & $135.64 \pm 18.51$ & $109.64 \pm 50.12$ & $212.87 \pm 41.82^{*}$ \\
\hline
\end{tabular}

Values represent: mean $\pm \mathrm{SD}$; compared with $\mathrm{RPE}{ }^{*} \mathrm{P}<0.05 ;{ }^{* *} \mathrm{P}<0.01$; SGT: Shao-yao Gan-cao Tang; JZGH: Jing-Zhi-Guan-Xin.

Table 6. Pharmacokinetics of PF, either in pure form or in DSS following oral administration to normal and vascular dementia rats.

\begin{tabular}{ccccc}
\hline \multirow{2}{*}{ Parameters } & \multicolumn{2}{c}{ Normal Rats } & \multicolumn{2}{c}{ Vascular Dementia Rats } \\
\cline { 2 - 5 } & PF & PF-DSS & PF & PF-DSS \\
\hline $\mathrm{t}_{1 / 2}(\mathrm{~h})$ & $5.95 \pm 1.53$ & $6.94 \pm 1.22$ & $11.97 \pm 1.22$ & $9.64 \pm 2.61$ \\
MRT $(\mathrm{h})$ & $5.25 \pm 1.05$ & $8.16 \pm 1.88$ & $10.47 \pm 1.30$ & $10.58 \pm 3.83$ \\
AUC $(\mu \mathrm{g} \cdot \mathrm{h} / \mathrm{mL})$ & $7.89 \pm 1.73$ & $5.64 \pm 0.71$ & $11.95 \pm 1.75$ & $8.92 \pm 0.99$ \\
\hline
\end{tabular}

Values represent: mean \pm SD; PF: Paeoniflorin; DSS: Danggui-Shaoyao-San.

showed significant delay in absorption half life, prolonged mean resident time and an increase AUC compared to normal rats with $t_{1 / 2}$ and AUC. These observations shows that the bioavailability of PF in DSS in VD was improved compared to PF in DSS and PF alone in NR [43]. Liu et al. also reported that the $\mathrm{C}_{\max }$ of $\mathrm{PF}$ in DSS $[(143 \pm 65) \mathrm{ng} / \mathrm{mL}]$ was significantly lower than PF alone $[(659 \pm 147) \mathrm{ng} / \mathrm{mL}]$, with a corresponding AUC of PF in DSS [(242 \pm 126$) \mathrm{ng} \cdot \mathrm{h} / \mathrm{mL}]$ significantly lower than PF alone $[(722 \pm 158) \mathrm{ng} \cdot \mathrm{h} / \mathrm{mL}]$. While a significant higher $\mathrm{C}_{\max }[2132 \pm 560 \mathrm{ng} / \mathrm{mL}$.] with a remarkable increase AUC of PF in RP-A [2259 $\pm 910 \mathrm{ng} \cdot \mathrm{h} / \mathrm{mL}]$ after oral administration to rats (calculated at a normalized dose of $20 \mathrm{mg} / \mathrm{kg} \mathrm{PF}$ ) using liquid chromatography-tandem mass spectrometry method. The contradiction of bioavailability of PF in SGT and DSS may be attributed to poor standardization from sourcing of raw material to final product. This may therefore contribute to differences in chemical composition and drug-drug interactions.

Huangqin-Tang, a compound prescription consisting of four medicinal herbs (i.e., Radix Scutellariae baicalensis, Radix P. lactiflora, Radix G. uralensis and Ziziphus jujuba Mill.) showed no significant difference in the pharmacokinetic parameters of PF in compound prescription compared with the single herb extract of $P$. lactifola (Table 7) after oral administration containing 10 $\mathrm{mg} / \mathrm{kg}$ PF content using a simple validated HPLC method [26]. Similarly, the results of a study (Table 8)
Table 7. Pharmacokinetics parameters of PF in HuangqinTang and $P$. lactiflora.

\begin{tabular}{ccc}
\hline Parameters & Paeonia lactiflora & Huangqin-Tang \\
\hline $\mathrm{t}_{1 / 2 \alpha}(\mathrm{h})$ & $0.16 \pm 0.00$ & $0.27 \pm 0.08$ \\
$\mathrm{t}_{1 / 2 \beta}(\mathrm{h})$ & $2.17 \pm 0.35$ & $2.46 \pm 1.01$ \\
$\mathrm{t}_{\max }(\mathrm{h})$ & $0.65 \pm 0.28$ & $0.97 \pm 0.06$ \\
$\mathrm{C}_{\max }(\mathrm{ng} / \mathrm{mL})$ & $1626.75 \pm 541.09$ & $1485.65 \pm 652.21$ \\
$\mathrm{AUC}_{0-\infty}(\mathrm{ng} \cdot \mathrm{h} / \mathrm{mL})$ & $24729.91 \pm 1630.99$ & $6273.19 \pm 2140.36$ \\
$\mathrm{MRT}(\mathrm{h})$ & $14.78 \pm 8.31$ & $18.04 \pm 5.64$ \\
\hline
\end{tabular}

Values represent: mean $\pm \mathrm{SD}$.

Table 8. Pharmacokinetics parameters of PF following oral administration of paeoniflorin solution and Si Ni San extracts to rats.

\begin{tabular}{ccc}
\hline Parameters & PF & Si Ni San \\
\hline $\mathrm{t}_{1 / 2 \alpha}(\mathrm{min})$ & $3.42 \pm 1.57$ & $18.25 \pm 17.30$ \\
$\mathrm{t}_{1 / 2 \beta}(\mathrm{min})$ & $518.42 \pm 132.22$ & $381.82 \pm 91.35$ \\
$\mathrm{t}_{\max }(\mathrm{min})$ & $22.31 \pm 8.28$ & $34.38 \pm 26.78$ \\
$\mathrm{C}_{\max }(\mathrm{ng} / \mathrm{L})$ & $640.18 \pm 125.86$ & $250.45 \pm 36.17$ \\
\hline
\end{tabular}

Values represent: mean $\pm \mathrm{SD}$.

conducted by Liu et al. [17] on the pharmacokinetics of PF between pure PF and Si Ni San, a TCM formulation composed of Radix Bupleurum falcatum L., Fructus immaqturus, Radix P. lactiflora, and Radix G. uralensis following oral administration were comparable. The pharmacokinetic parameters for PF in Si Ni San and PF alone were $\mathrm{C}_{\max }(250.45 \pm 36.17) \mu \mathrm{g} / \mathrm{L}, \mathrm{t}_{\max }(34.38 \pm$ 26.78) $\mathrm{min}$; and $\mathrm{C}_{\max }(640.18 \pm 125.86) \mu \mathrm{g} / \mathrm{L}, \mathrm{t}_{\max }(22.31$ $\pm 8.28) \mathrm{min}$, respectively. The low bioavailability of $\mathrm{PF}$ in Si Ni San indicates that instead of PF responsible for the pharma cological effects, possibly its metabolites by intestinal bacteria and liver promoted by other components in Si Ni San [44].

Tang-Min-Ling-Wan (TMLW), another prescription of TCM containing Radix Scutellariae, Radix Paeoniae Alba, Rhizoma Coptidis, Radix et Rhizoma Rhei, Fructus 
Aurantii Immaturus, Radix Bupleuri, Rhizoma Pinelliae, is used for hyperlipidemia and hyperglycemia and increasing insulin expression and antioxidant enzyme activity. It is used clinically in the treatment of type 2 diabetes mellitus and diabetic complications [45]. An HPLC-MS/MS method was developed and applied to pharmacokinetics of $\mathrm{PF}$ after oral administration of 55 $\mathrm{mg} / \mathrm{kg}$ PF content of TWLW $(11.0 \mathrm{~g} / \mathrm{kg})$ and RP-A extract $(0.63 \mathrm{~g} / \mathrm{kg}$ extract $)$ by Tong et al. The peak concentration of PF in TWLW occurred more rapidly $\left[\mathrm{t}_{\max }=\right.$ $(0.28 \pm 0.09) \mathrm{h}]$ but with a higher plasma concentration $\left[\mathrm{C}_{\max }=(1591 \pm 416.9) \mathrm{ng} / \mathrm{mL}\right]$ whiles the peak concentration of PF in RP-A extract occurred slowly [ $\mathrm{t}_{\max }=$ $(0.89 \pm 0.27) \mathrm{h}]$ but with a lower plasma concentration $\left[\mathrm{C}_{\max }=(301.3 \pm 96.81) \mathrm{ng} / \mathrm{mL}\right]$ However there was no significant differences of PF bioavailability between TWLW $\left[\mathrm{t}_{1 / 2}=(2.17 \pm 0.76) \mathrm{h} ; \mathrm{AUC}_{0-\mathrm{t}}=(1443 \pm 207.5)\right.$ $\mathrm{ng} \cdot \mathrm{h} / \mathrm{mL}$. $]$ and RP-A extract $\left[\mathrm{t}_{1 / 2}=(1.97 \pm 0.63) \mathrm{h}\right.$; $\left.\mathrm{AUC}_{0-\mathrm{t}}=(1495 \pm 521.2) \mathrm{ng} \cdot \mathrm{h} / \mathrm{mL}\right]$. Salmul-tan is an herbal medicine prescribed in South Korea. It is also known as Si-Wu-Tang or Shimotsu-to, prescribe in China and Japan, respectively. It is used traditionally for palpitation, amenorrhea, fatigue, dizziness. Salmul-tan or Si-Wu-Tang or Shimotsu-to is composed of Angelica gigas, Cnidium officinale, Paeonia lactiflora and Rehmannia glutinosa. Hwang et al. [46] investigated whether food and gender could influence the pharmacokinetic profile of PF following a single oral dose $(80 \mathrm{mg} / \mathrm{kg})$ of $\mathrm{Si}-\mathrm{Wu}$-Tang to rats using an HPLC method. The results showed no significant difference by gender difference. However, food intake significantly, $P<0.05$, increased the availability $[(\mathrm{F}(\mathrm{rel})=2.21)]$ and extent of absorption of PF compared to fast state with increased $\mathrm{C}_{\max }[(1.10 \pm$ 0.35 vs $0.47 \pm 0.29) \mu \mathrm{g} / \mathrm{mL}]$ and $\mathrm{AUC}_{0-\infty}[(3.12 \pm 1.61)$ vs $(1.41 \pm 0.89) \mu \mathrm{g} \cdot \mathrm{h} / \mathrm{mL}]$, respectively.

Buyang Huanwu decoction (BYHWD) is a Chinese traditional compound. BYHWD is composed of Radix Astragalus membranaceus, Radix Angelicae Sinensis, Radix P. lactiflora Pall.; Radix Ligustici wallichii, Carthamus tinctorius L, Amygdalus persica L.; and Pheretima aspergillum. It has been developed as a drug to treat stroke-induced disabilities and has proven effective in treating cerebrovascular illnesses [47]. A reversed phaseHPLC method developed and applied in a pharmacokinetic studies of PF after intravenous administration of BYHWD and total glycosides to rats fitted a two compartmental model while an oral administration to rats by Zhang et al. [48] fitted a one compartmental model with first order absorption. Wuji Pill is a prescription of a traditional Chinese medicine commonly used to treat gastro-intestinal disorder. It consists of three herbs such as Rhizoma Coptidis, Fructus Evodiae Rutaecarpae and Radix Paeoniae Alba. A pharmacokinetic study after oral administration of Wuji Pill to rats using a developed LC-MS/MS method by Yuan et al. [49] to simultaneously determine six alkaloids [palmatine, jatrorrhizine, berberine coptisine (from Rhizoma Coptidis); Evodiamine, rutacarpine (from Fructus Evodiae Rutaecarpae)] and one monoterpene glycoside [paeoniflorin, (from Radix Paeoniae Alba)] showed that PF of Radix Paeoniae Alba fitted a two compartmental model. This is comparable to the result of an intravenous administration of PF alone reported by Wang et al. [22]. However, other compound prescriptions discussed in this review fits one compartmental model. This shows that the use of multiple herbs in a prescription can alter the pharmacokinetic status as well as its pharmacological effects.

\section{Influence Factors on PF Absorption}

\subsection{Using the Everted Rat Gut Sac Model}

The everted rat gut sac model [50] has also been used to establish that PF is not metabolised in the intestine. This showed a total recovery rate (in the serosal side, mucosal side and gut side tissue) higher than $97 \%$ and an uptake in the sac tissue about $10 \%$ with a saturation of PF absorption in to the sac content at $80 \mu \mathrm{M}$ [51]. The possibility that an energy-dependent carrier-mediated transport may be involved in the PF intestinal absorption has been speculated, since in vivo studies with an unrestricted conscious rat demonstrated that with co-administration with sinomenine $(90 \mathrm{mg} / \mathrm{kg})$, the peak plasma concentration of $\mathrm{PF}$ in rats was elevated, the peak time delayed, $\mathrm{AUC}_{0-\mathrm{t}}$ increased with prolonged MRT, clearance decreased and volume of distribution declined [52]. A similar outcome was reported upon co-administration of $\mathrm{PF}$ and glycyrrhizin acid [53] (Figure 2).

In the everted rat gut system the fraction of PF in the sac content was nearly elevated to 1.5 -fold and 2.5 -fold, respectively, when the gut sac was treated with $16 \mu \mathrm{M}$ and $136 \mu \mathrm{M}$ sinomenine in TC 199 medium for $45 \mathrm{~min}$ of incubation. Similarly, treatment of the gut sac with $100 \mu \mathrm{M}$ verapamil and $1.3 \mathrm{mM}$ quinidine significantly increased PF absorption in the sac content to 2.1-fold and 1.5 -fold, respectively. These elevated levels of absorption of $\mathrm{PF}$ in the presence of inhibitors were consistent with that of digoxin $(113 \mu \mathrm{M})$ a P-glycoprotein substrate, which was increasingly absorbed to about 2.5 -fold when co-incubated with sinomenine $(136 \mu \mathrm{M})$ relative to the non-sinomenine treated gut sac [51]. Studies on the effect of glycyrrhizin on the intestinal absorption of PF by the everted rat sac model also showed that PF could be absorbed in the duodenum, jejunum, ileum and colon of rats and glycyrrhizin can improve the efflux of PF from intestinal cells. These findings from the everted rat gut system therefore suggest that PF is not metabolised in the 
intestine and that its low bioavailability may be due to P-gp mediated efflux, a hypothesis that was partly in conformity with the findings of Liu et al. [27] who investigated the mechanism for the poor oral bioavailability of $\mathrm{PF}$ and the role of intestinal disposition and interaction with sinomenine using a single-pass four site rat intestinal perfusion model and a cultured Caco- 2 cell model.

\subsection{Using the Rat Perfusion and Caco-2 Cells Models}

In both model systems, absorption of PF was shown to be very poor. In the Caco- 2 cell model, the apparent permeability from the apical to the basolateral was $0.48 \times$ $10^{-6} \mathrm{~cm} / \mathrm{s}$. This value is similar to poorly absorbed compounds such as mannitol at $1.7 \times 10^{-6} \mathrm{~cm} / \mathrm{s}$ and sulfasalazine at $0.34 \times 10^{-6} \mathrm{~cm} / \mathrm{s}$ and is 23 times lower than propranolol at $11.3 \times 10^{-6} \mathrm{~cm} / \mathrm{s}$, a highly absorbed compound $[54,55]$. The rat intestinal perfusion model also showed a similar results with $\mathrm{P}_{\text {eff }}^{*}<0.4$ in all four intestines lower than propranolol $\left(\mathrm{P}_{\text {eff }}^{*}>3.5\right)$ but similar to rutin $\left(\mathrm{P}_{\text {eff }}^{*}<0.58\right)$ and mannitol with $\mathrm{P}_{\text {eff }}^{*}<0.3$ [56]. Furthermore, in the perfusate model predominant intestinal metabolites of PF such as paeoniflorigenin and benzoic acid were found. The presence of the metabolites were not affected in the presence of cyclosporine A (5 $\mu \mathrm{M})$ or sinomenine $(100 \mu \mathrm{M})$, while absorption increased in the jejunum ( $45 \%$ to $55 \%)$ and terminal ileum $(80 \%$ to $86 \%$ ) but not in the duodenum [27].

Similarly, in the Caco-2 cell model, absorptive transport of PF was significantly $(P<0.05)$ increased $38 \%$ by sinomenine, $27 \%$ by verapamil and $41 \%$ by cyclosporine A. In contrast, its secretory transport was significantly $(P$ $<0.01$ ) decreased to $45 \%$ by sinomenine, $35 \%$ by verapamil and $37 \%$ by cyclosporine A. MRP inhibitors MK571 and leukotriene $\mathrm{C} 4$ did not affect transport of PF. Sinomenine was also shown to significantly increase the absorptive transport of digoxin and significantly decrease its secretory transport.

\section{Conclusion}

PF administered alone has a low bioavailability. However in the presence of other phytochemicals, either in pure form or in single or multiple herb prescriptions, the bioavailability or the pharmacokinetics profiles may or may not be significantly enhanced. This could consequently have direct impact on its pharmacological actions. Different methods to determine the cause of its low bioavailability have shown that PF is poorly absorbed due to low lipophilicity, efflux through P-glycoproteins, hydrolytic degradation in the intestine by intestinal brush border LPH and certain esterases, as well as intestinal bacteria and without hepatic metabolism. However, the bioavailability may be improved with P-gp inhibitors (sinomenine) and LPH inhibitors. Methods that could be used to determine the mechanism of the low bioavailability of a compound needs serious consideration to be able to give good predictions about the in vivo course of the compound. Further work needs to be done to confirm the effect of glycyrrhizin acid on the improvement of the bioavailability of PF using the Caco-2 cell model and/or MDCK II-MDR 1 cells, and the four-site Perfusion model.

\section{Acknowledgements}

The Project Supported by Natural Science Foundation of Tianjin (No. 12JCZDJC26100); Research Fund for the Doctoral Program of Higher Education [RFDP, No. 20121210110011]; National Basic Research Program of China (973 Program) [No. 2012CB724001]; Program for Changjiang Scholars and Innovative Research Team in University (PCSIRT, No.IRT0973).

\section{REFERENCES}

[1] "National Institute for the Control of Pharmaceutical and Biological Products," Color Atlas of Chinese Traditional Drugs, Vol. 1, Science Press, Beijing, 1987.

[2] J. Y. Geng, W. Q. Huang, T. C. Ren and X. F. Ma, "Medicinal Herbs," New World Press, Beijing, 1990.

[3] J. Bruneton, "Pharmacognosy, Phytochemistry, Medicinal Plants," Lavoisier, Paris, 1995.

[4] Committee of the Pharmacopoeia of PR China, "Pharmacopoeia of PR China," Part I. Chemical Industry Press, Beijing, 2010.

[5] I. N. Kostova, M. F. Simeonov and D. I. Todorova, "A Monoterpene Glucoside from Paeonia peregrina Roots," Phytochemistry, Vol. 47, No. 7, 1998, pp. 1303-1307. http://dx.doi.org/10.1016/S0031-9422(97)00683-3

[6] Q. Wang, R. X. Liu, H. L. Yu, P. Liu, Z. T. Liu, K. S. Bi and D. A. Guo, "Studies on HPLC Fingerprint of White Peony Roots and Red Peony Roots," Chinese Pharmaceutical Journal, Vol. 42, No. 8, 2007, pp. 581-584.

[7] A. Bracaa, P. V. Kiem, P. H. Yen, N. X. Nhiem, T. H. Quang, N. X. Cuong and C. V. Minh, "New Monoterpene Glycosides from Paeonia lactiflora," Fitoterapia, Vol. 79, No. 2, 2008, pp. 117-120. http://dx.doi.org/10.1016/j.fitote.2007.11.001

[8] K. Washida, Y. Itoh, T. Iwashita and K. Nomoto, "Androgen Modulators from the Roots of Paeonia lactiflora (Paeoniae Radix) Grown and Processed in Nara Prefecture," Chemical \& Pharmaceutical Bulletin, Vol. 57, No. 9, 2009, pp. 971-974. http://dx.doi.org/10.1248/cpb.57.971

[9] K. Washida, T. Yamagaki, T. Iwashita and K. Nomoto, "Two New Galloylated Monoterpene Glycosides, 4-OGalloylalbiflorin and 4-O-Galloylpaeoniflorin, from the 
Roots of Paeonia lactiflora (Paeoniae Radix) Grown and Processed in Nara Prefecture," Chemical \& Pharmaceutical Bulletin, Vol. 57, No. 10, 2009, pp. 1150-1152. http://dx.doi.org/10.1248/cpb.57.1150

[10] J. Yamahara, T. Yamada, H. Kimura, T. Sawada and H. Fujimura, "Biologically Active Principles of Crude Drugs. II. Anti-Allergic Principles in 'Shoseiryu-To' Anti-Inflammatory Properties of Paeoniflorin and Its Derivatives," Journal of Pharmacobio-Dynamics, Vol. 5, No. 11, 1982, pp. 921-929.

http://dx.doi.org/10.1248/bpb1978.5.921

[11] H. Ishida, M. Takamatsu, K. Tsuji and T. Kosuge, "Studies on Active Substances in Herbs Used for Oketsu ('Stagnant Blood') in Chinese Medicine on the Anticoagulative Principle in Moutan cortex," Chemical \& Pharmaceutical Bulletin, Vol. 35, No. 2, 1987, pp. 846-848. http://dx.doi.org/10.1248/cpb.35.846

[12] K. Dezaki, I. Kimura, K. Miyahara and M. Kimura, "Complementary Effects of Paeoniflorin and Glycyrrhizin on Intracellular $\mathrm{Ca}^{2+}$ Mobilization in the Nerve-Stimulated Skeletal Muscle of Mice," Japanese Journal of Pharmacology, Vol. 69, No, 3, 1995, pp. 281-284. http://dx.doi.org/10.1254/jip.69.281

[13] H. Ohta, K. Matsumoto, M. Shimizu and H. Watanabe, "Paeoniflorin Attenuates Learning Impairment of Aged Rats in Operant Brightness Discrimination Task," Pharmacology Biochemistry and Behavior, Vol. 49, No. 1, 1994, pp. 213-217. http://dx.doi.org/10.1016/0091-3057(94)90478-2

[14] H. Ohta, J. W. Ni, K. Matsumoto, H. Watanabe and M. Shimizu, "Peony and Its Major Constituent, Paeoniflorin, Improve Radial Maze Performance Impaired by Scopolamine in Rats," Pharmacology Biochemistry and Behavior, Vol. 45, No. 3, 1993, pp. 719-723. http://dx.doi.org/10.1016/0091-3057(93)90530-7

[15] K. Tabata, K. Matsumoto and H. Watanabe, "Paeoniflorin a Major Constituent of Peony Root Reverses Muscarinic M1-Receptor Antagonist-Induced Suppression of LongTerm Potentiation in the Rat Hippocampal Slice," Japanese Journal of Pharmacology, Vol. 83, No. 1, 2000, pp. 25-30. http://dx.doi.org/10.1254/jjp.83.25

[16] F. L. Hsu, C. W. Lai and J. T. Cheng, "Antihyperglycemic Effects of Paeoniflorin and 8-Debenzoylpaeoniflorin, Glucosides from the Root of Paeonia lactiflora," Planta Medica, Vol. 63, No. 4, 1997, pp. 323-325. http://dx.doi.org/10.1055/s-2006-957692

[17] D. Z. Liu, K. Q. Xie, X. Q. Ji, Y. Ye, C. L. Jiang and X. Z. Zhu, "Neuroprotective Effect of Paeoniflorin on Cerebral Ischemic Rat by Activating Adenosine A1 Receptor in a Manner Different from Its Classical Agonists," British Journal of Pharmacology, Vol. 146, No. 4, 2005, pp. 604-611. http://dx.doi.org/10.1038/sj.bjp.0706335

[18] C. L. Hsieh, C. Y. Cheng, T. H. Tsai, I. H. Lin, C. H. Liu, S. Y. Chiang, et al., "Paeonol Reduced Cerebral Infarction Involving the Superoxideanion and Microglia Activation in Ischemia-Reperfusion Injured Rats," Journal of Ethnopharmacology, Vol. 106, No. 2, 2006, pp. 208-215. http://dx.doi.org/10.1016/j.jep.2005.12.027
[19] C. Chen, Y. Zhang, J. Chen and J. Li, "The Studies on Pharmacokinetics of Paeoniflorin," Chinese Pharmacological Bulletin, Vol. 5, 1990, pp. 299-302.

[20] G. L. Chen, C. H. Chen and S. Y. Xu, "The Studies on Pharmacokinetics of Paeoniflorin in Rabbits and Rats," Chinese Pharmacological Bulletin, Vol. 4, 1992, pp. 278280.

[21] S. Takeda , T. Isono, Y. Wakui , Y. Matsuzaki, H. Sasaki, S. Amagaya and M. Maruno, "Absorption and Excretion of Paeoniflorin in Rats," Journal of Pharmacy and Pharmacology, Vol. 47, No. 12A, 1995, pp. 1036-1340. http://dx.doi.org/10.1111/j.2042-7158.1995.tb03293.x

[22] C. H. Wang, R. Wang, X. M. Cheng, Y. Q. He, Z. T. Wang, C. Wu and J. Cao, "Comparative Pharmacokinetic Study of Paeoniflorin after Oral Administration of Decoction of Radix Paeoniae Rubra and Radix Paeoniae Alba in Rats," Journal of Ethnopharmacology, Vol. 117, No. 3, 2008, pp. 467-472. http://dx.doi.org/10.1016/j.jep.2008.02.035

[23] Y. F. Li, M. Wang, X. Y. Wang, H. S. Yu, L. P. Kang, B. P. Ma, J. X. Ruan and Z. Q. Zhang, "Pharmacokinetic Properties of Albiflorin and Paeoniflorin after Oral Administration of Pure Compound, Radix Paeoniae Alba Extract and Danggui-Shaoyao-San Extract to Rats," Journal of Asian Natural Products Research, Vol. 13, No. 2, 2011, pp. 117-127. http://dx.doi.org/10.1080/10286020.2010.546353

[24] S. Takeda, T. Isono, Y. Wakui, Y. Mizuhara, S. Amagaya, M. Maruno and M. Hattori, "In Vivo Assessment of Extrahepatic Metabolism of Paeoniflorin in Rats: Relevance to Intestinal Floral Metabolism," Journal of Pharmacy and Pharmacology, Vol. 49, No, 1, 1997, pp. 35-39. http://dx.doi.org/10.1111/j.2042-7158.1997.tb06748.x

[25] M. Hattori, Y. Z. Shu, M. Shimizu, T. Hayashi, N. Morita, K. Kobashi, G. J. Xu and T. Namba, "Metabolism of Paeoniflorin and Related Compounds by Human Intestinal Bacteria," Chemical and Pharmaceutical Bulletin, Vol. 33, No. 9, 1985, pp. 3838-3846. http://dx.doi.org/10.1248/cpb.33.3838

[26] F. Zuo, Z. M. Zhou, Q. Zhang, D. Mao, Y. L. Xiong, Y. L. Wang, M. Z. Yan and M. L. Liu, "Pharmacokinetic Study on the Multi-Constituents of Huangqin-Tang Decoction in Rats," Biological \& Pharmaceutical Bulletin, Vol. 26, No. 7, 2003, pp. 911-919. http://dx.doi.org/10.1248/bpb.26.911

[27] Z. Q. Liu, Z. H. Jiang, L. Liu and M. Hu, "Mechanisms Responsible for Poor Oral Bioavailability of Paeoniflorin: Role of Intestinal Disposition and Interactions with Sinomenine," Pharmaceutical Research, Vol. 23, No. 12, 2006, pp. 2768-2780. http://dx.doi.org/10.1007/s11095-006-9100-8

[28] J. F. Ye, H. L. Duan, X. M. Yang, W. Yan and X. Zheng, "Anti-Thrombosis Effect of Paeoniflorin: Evaluated in a Photochemical Reaction Thrombosis Model in Vivo," Planta Medica, Vol. 67, No. 8, 2001, pp. 766-767. http://dx.doi.org/10.1055/s-2001-18364

[29] Y. M. Wu, H. P. Xu, C. T. Wang, H. Yang and G. Ju, "Protective Effects of Paeoniflorin on Cultured Cortical 
Neurons of Mice," Chinese Journal of Pharmacology and Toxicology, Vol. 16, No. 3, 2002, pp. 172-175.

[30] R. Wang, “A Comparison on Pharmacological Actions between Radix Paeoniae Rubra and Radix Paeoniae Alba," China Journal of Experimental Traditional Medical Formulae, Vol. 16, No. 7, 2010, pp. 112-114.

[31] H. Z. Wu and N. S. Xiong, "Pharmacological Research and Clinical Application of Radix Paeoniae Alba," Chinese Journal of Hospital Pharmacy, Vol. 18, No. 4, 1988, p. 172.

[32] C. Feng, M. Liu, X. Shi, W. Yang, D. Kong, K. Duan and Q. Wang, "Pharmacokinetic Properties of Paeoniflorin, Albiflorin and Oxypaeoniflorin after Oral Gavage of Extracts of Radix Paeoniae Rubra and Radix Paeoniae Alba in Rats," Journal of Ethnopharmacology, Vol. 130, No. 2, 2010, pp. 407-413.

http://dx.doi.org/10.1016/j.jep.2010.05.028

[33] J. Wu, N. Yao and D. W. Wang, "Determination of Paeoniflorin in Rat Plasma by HPLC-MS/MS and Its Pharmacokinetics," China Journal of Chinese Material Medica, Vol. 33, No. 20, 2008, pp. 2369-2273.

[34] T. Bao, Q. Yang, Y. Zhang, Y. Dong, Y. Li and X. Zhu, "Pharmacokinetics Study on Paeoniflorin in Radix Paeoniae Alba Extract by LC-MS," China Journal of Chinese Material Medica, Vol. 35, No. 9, 2010, pp. 1193-1196.

[35] F. Jiang, Y. Zhao, J. Wang, S. Wei, Z. Wei, R. Li, Y. Zhu, Z. Sun and X. Xiao, "Comparative Pharmacokinetic Study of Paeoniflorin and Albiflorin after Oral Administration of Radix Paeoniae Rubra in Normal Rats and the Acute Cholestasis Hepatitis Rats," Fitoterapia, Vol. 83, No. 2, 2012, pp. 415-421. http://dx.doi.org/10.1016/i.fitote.2011.12.009

[36] Y. Tanaka, L. M. Aleksunes, Y. J. Cui and C. D. Klaassen, "ANIT-Induced Intrahepatic Cholestasis Alters Hepatobiliary Transporter Expression via Nrf2-Dependent and Independent Signaling," Toxicological Sciences, Vol. 108, No. 2, 2009, pp. 247-257. http://dx.doi.org/10.1093/toxsci/kfp020

[37] Y. Ohta, M. Kongo-Nishimura, T. Hayashi, A. Kitagawa, T. Matsura and K. J. Yamada, "Saikokeishito Extract Exerts a Therapeutic Effect on Alpha-Naphthylisothiocyanate-Induced Liver Injury in Rats through Attenuation of Enhanced Neutrophil Infiltration and Oxidative Stress in the Liver Tissue," Journal of Clinical Biochemistry and Nutrition, Vol. 40, No. 1, 2007, pp. 31-41. http://dx.doi.org/10.3164/jcbn.40.31

[38] X. He, D. Xing, Y. Ding, Y. Li, L. Xu and L. Du, "Effects of Cerebral Ischemia-Reperfusion on Pharmacokineticfate of Paeoniflorin after Intravenous Administration of Paeoniae Radix Extract in Rats," Journal of Ethnopharmacology, Vol. 94, No. 2, 2004, pp. 339-344. http://dx.doi.org/10.1016/j.jep.2004.06.009

[39] L. C. Chen, M. H. Chou, M. F. Lin and L. L. Yang, "Pharmacokinetics of Paeoniflorin after Oral Administration of Shaoyao Gancao Tang in Mice," Japanese Journal of Pharmacology, Vol. 88, No.3, 2002, pp. 250-255. http://dx.doi.org/10.1254/jip.88.250

[40] L. Shen, R. W. Hu , X. Lin, W. J. Cong, Y. L. Hong, Y.
Feng, D. S. Xu and K. F. Ruan, "Pharmacokinetics of Characteristic Effective Ingredients from Individual and Combination Shaoyao and Gancao Treatement in Rats Using HPLC Fingerprinting," European Journal of Drug Metabolism and Pharmacokinetics, Vol. 37, No. 2, 2011. pp. 133-140.

http://dx.doi.org/10.1007/s13318-011-0052-y

[41] P. Gan, M. Zhong, X. Huang, M. Sun, Y. Wang, Y. Xiao, et al., "Pharmacokinetic Comparisons of Albiflorin and Paeoniflorin after Oral Administration of Shaoyao GacaoTang and Single Herb Paeony Decoction to Rats," Planta Medica, Vol. 78, No. 3, 2012, pp. 237-243. http://dx.doi.org/10.1055/s-0031-1280366

[42] X. G. Yang, B. Peng, G. H. Zhang, L. L. Wei, S. F. Nie and W. S. Pan, "Studies of the Pharmacokinetics of Paeoniflorin in Two Jing-Zhi-Guan-Xin Formulations after Oral Administration to Beagle Dogs," Journal of Pharmaceutical and Biomedical Analysis, Vol. 41, No. 1, 2006, pp. 320-324. http://dx.doi.org/10.1016/j.jpba.2005.11.004

[43] J. Liu, J. S. Wang and L. Y. Kong, "Comparative Pharmacokinetics of Paeoniflorin in Plasma of Vascular Dementia and Normal Rats Orally Administrated with Danggui-Shaoyao-San or Pure Paeoniflorin," Fitoterapia, Vol. 82, No. 3, 2011, pp. 466-473. http://dx.doi.org/10.1016/j.fitote.2010.12.004

[44] D. F. Liu, L. Zhang and T. Chen, "Pharmacokinetics Study on Paeoniflorin in Sini Sanghai," China Journal of Experimental Traditional Medical Formulae, Vol. 11, No. 2, 2005, pp. 36-38.

[45] L. Tong, M. Wan, D. Zhou, J. Gao, Y. Zhu and K. Bi, "LC-MS/MS Determination and Pharmacokinetic Study of Albiflorin and Paeoniflorin in Rat Plasma after Oral Administration of Radix Paeoniae Alba Extract and TangMin-Ling-Wan," Biomedical Chromatography, Vol. 24, No. 12, 2010, pp. 1324-1331. http://dx.doi.org/10.1002/bmc.1443

[46] Y. H. Hwang, T. Kim, W. K. Cho, D. Jang, J. H. Ha and J. Y. Ma, "Food- and Gender-Dependent Pharmacokinetics of Paeoniflorin after Oral Administration with SamulTang in Rats," Journal of Ethnopharmacology, Vol. 142, No. 1, 2012, pp. 161-167. http://dx.doi.org/10.1016/j.jep.2012.04.032

[47] Q. Wang, "Yilin Gaicuo," People's Medical Publishing House, Beijing, 2005.

[48] J. Zhang, G. Yang, R. Lin and Z. Hu, "Determination of Paeoniflorin, Calycosin-7-O- $\beta$-D-glucoside, Ononin, Calycosin and Formononetin in Rat Plasma after Oral Administration of Buyang Huanwu Decoction for Their Pharmacokinetic Study by Liquid Chromatography-Mass Spectrometry," Biomedical Chromatography, Vol. 25, No. 4, 2011, pp. 450-457. http://dx.doi.org/10.1002/bmc.1466

[49] J. Yuan, Y. Wang, A. Rui, S. Wang, S. J. Li, J. Y. Jia, A. S. W. Bligh, X. H. Wang and Y. M. Ma, "Simultaneous Determination of Six Alkaloids and One Monoterpene in Rat Plasma by Liquid Chromatography-Tandem Mass Spectrometry and Pharmacokinetic Study after Oral Administration of a Chinese Medicine Wuji Pill," Journal of Chromatography B, Vol. 895-896, 2012, pp. 154-161.

[50] R. Bouer, L. Barthe, C. Philibert, C. Tournaire, J. Wood- 
ley and G. Houin, "The Role of P-Glycorprotein and Intracellular Metabolism in the Intestinal Absorption of Methadone: In Vitro Studies Using the Rat Everted Intestinal Sac," Fundamental \& Clinical Pharmacology, Vol. 13, No. 4, 1999, pp. 494-500. http://dx.doi.org/10.1111/j.1472-8206.1999.tb00009.x

[51] K. Chan, Z. Q. Liu, Z. H. Jiang, H. Zhou, Y. F. Wong, H. X. Xu and L. Liu, "The Effects of Sinomenine on Intestinal Absorption of Paeoniflorin by the Everted Rat Gut Sac Model," Journal of Ethnopharmacology, Vol. 103, No. 3, 2006, pp. 425-432. http://dx.doi.org/10.1016/j.jep.2005.08.020

[52] Q. L. Zhong, Z. Hua, L. Liang, H. J. Zhi, F. W. Yuen, X. Ying, C. Xiong, X. X. Hong and C. Kelvin, "Influence of Co-Administrated Sinomenine on Pharmacokinetic Fate of Paeoniflorin in Unrestrained Conscious Rats," Journal of Ethnopharmacology, Vol. 99, No. 1, 2005, pp. 61-67. http://dx.doi.org/10.1016/j.jep.2005.01.052

[53] L. Shen, L. Zhang, Y. Feng, D. S. Xu and X. Lin, "Phar- macokinetics of Paeonia lactiflora and G lycyrrhiza uralensis Compound, " Chinese Traditional Patent Medicine, Vol. 31, No. 3, 2009, pp. 374-377.

[54] E. Liang, J. Proudfoot and M. Yazdanian, "Mechanisms of Transport and Structure of Permeability Relationship of Sulfasala-Zine and Its Analogs in Caco-2 Cell Monolayers," Pharmaceutical Research, Vol. 17, No. 10, 2000, pp.1168-1174.

http://dx.doi.org/10.1023/A:1026450326712

[55] E. J. Jeong, Y. Liu, H. Lin and M. Hu, "In Situ SinglePass Perfused Rat Intestinal Model for Absorption and Metabolism," In: N. J. Totowa, Ed., Optimization in Drug Discovery: In Vitro Methods, Springer, Berlin, 2004, pp. 65-76. http://dx.doi.org/10.1385/1-59259-800-5:065

[56] Y. Liu, Y. Liu, Y. Dai, L. Y. Xun and M. Hu, "Enteric Disposition and Recycling of Flavonoids and Ginkgo Flavonoids," Journal of Alternative and Complementary Medicine, Vol. 9, No. 5, 2003, pp. 631-640. 